\title{
Cellular responses against Schistosoma mansoni in immunized Balb/c mice with soluble proteins from intermediate host, Biomphalaria pfeifferi
}

\author{
KENNEDY M. KURIA ${ }^{1 *}$, REBECCA WAIHENYA ${ }^{2}$, HELLEN KUTIMA ${ }^{2}$, PENINNAH NJOKI $^{1}$ and \\ DORCAS S. YOLE 3 \\ ${ }^{1}$ Mount Kenya University, P.O Box 342, Thika, Kenya \\ ${ }_{2}^{2} J o m o$ Kenyatta University of Agriculture and Technology P.O. Box 62000, Nairobi, Kenya \\ ${ }^{3}$ Institute of Primate Research, P.O Box 24481 Karen, Nairobi, Kenya
}

\begin{abstract}
Scores of millions of people around the world are infected by Schistosoma mansoni causing considerable morbidity, mortality and loss of productivity. Safe chemotherapeutic agents have been used though there are challenges of re-infection due to resistance. Both epidemiological and experimental data suggest that acquired cell mediated immunity play significant roles in regulating the intensity of $S$. mansoni infection as well as its patho-physiologic sequelae. Improved control of this trematode parasite may be obtained with immunization to enhance the resistance of individuals to risk of infection. This study investigated the cellular responses of mice immunized with soluble proteins from foot and digestive gland of the vector snail and challenged with S. mansoni. The proteins were used to immunize the experimental groups then challenged with the S. mansoni. The experimental groups were FT (immunized with foot protein) and DG (immunized with digestive gland). The parameters, which were analyzed to demonstrate protection, included; the worm counts and cellular (IFN- $\gamma$, IL-5 cytokines) responses. It was observed that, the experimental groups showed significant protection in terms of worm reduction and immune responses. The group vaccinated with foot protein showed higher protection $(87.5 \%)$ as compared to the group vaccinated with the digestive gland $(50 \%)$ in terms of worm reduction. Cytokines (IFN- $\gamma$ and IL-5) production was present in different levels during the assay time points which showed an aspect of protection. The Foot protein of the vector showed more immunizing power than the digestive gland. Research towards utilizing the two proteins as feasible vaccine candidates is encouraged.
\end{abstract}

Keywords: Schistosoma mansoni, Biomphalaria pfeifferi, IFN- $\gamma$, IL-5 cytokines, mice

\section{Introduction}

Schistosomiasis remains one of the neglected diseases whose search for a vaccine remains at large. No effective vaccine for the disease exists yet. Schistosomiasis affects over 200 million people worldwide, mainly in rural agricultural and peri-urban areas of developing countries, and approximately $10 \%$ suffer severe health complications from the infection (McManus et al., 2008). While chemotherapeutic drugs, such as praziquantel, oxamniquine and metrifonate, are currently considered safe and effective for the treatment of schistosomiasis, reinfection occurs frequently following drug treatment, thus a vaccine is sought to provide long-term solution (Oliveira et al., 2008). Several studies have determined that an age-dependent resistance to reinfection after cure of schistosomiasis through chemotherapeutic treatment occurs in some patients, suggesting that immunity to Schistosoma infection can be acquired and vaccination may be an effective option (McManus et al., 2008).

\footnotetext{
* Correspondence: Kennedy M. Kuria; E-mail: kenmuna2002@yahoo.com
} 
Consequently, the development of a vaccine against schistosomes remains a priority and immunological responses to infection remain a key component of this effort. The development of an anti-schistosome vaccine must take into account the association between anti-parasite immune responses and the development of severe disease. This is because protection and pathology in schistosomiasis are so self associated (Wilson, 1990). Additionally, experimental vaccination efforts have been successful in animal models of Schistosomiasis (McManus et al., 2008).

The essential function of antibodies in protective immunity is likely to be the induction of cytotoxic destruction of schistosomulum stage. Antibody-dependent cellmediated cytotoxicity (ADCC) appears to be the main mechanism of killing parasites in rodent, primate and human schistosomiasis (Capron \& Dessaint, 1985). Antibody-dependent cell-mediated cytotoxicity mechanisms involving pro-inflammatory cell populations (macrophages, eosinophils and platelets) as cellular partners and unusual antibody isotype as IgE or subclasses of IgG with anaphylactic properties have been implicated (Capron et al., 1987). These observations of IgE dependent cell-mediated killing, initially observed in rodents and confirmed in human schistosomiasis, raised the protective role of IgE antibodies against schistosomes (Capron \& Capron, 1994).

IgG4 antibody class is believed to counteract this IgE-mediated immunity since the odds of re-infection increase with decreasing IgE levels and increasing IgG4 levels. Therefore, IgG4 may inhibit the ADCC response by competing with IgE antibodies and blocking them from binding to the epitopes on the schistosome. Thus, immunity to reinfection is more related to the IgE-IgG4 balance than to the absolute levels of these two isotypes (Demeure et al., 1993).

The aim of this research was to investigate for a potential vaccine candidate against S. mansoni. The zoonotic nature of this species means that mice can be used as experimental hosts, which might reflect the host/parasite situation in humans better. The replication of schistosomes does not occur in the human host; hence a partially effective vaccine would prolong and reduce the development of morbidity, the signs of which do not appear until a sufficient number of egg-associated granulomas have been produced. According to Reynolds et al. (2004), the snail vector of S. mansoni, B. pfeifferi shares same antigens with the parasites explaining why the parasite is able to develop in this host. Therefore soluble proteins obtained from parts of the snail could offer protection against S. mansoni when used to immunize the host, hence this study sought to address this phenomenon. The soluble proteins from the foot and digestive glands were used to induce the cellular response of mice after which protection was assessed. The procedures done to the mice were according to the institute's guidelines on animal handling.

\section{Materials and Methods}

\section{Study site and study population}

The study was carried out at the Institute of Primate Research (IPR) which is a biomedical research institute using both non-human primate models and rodents.

Seventy two mice of eight weeks old BALC /c mice were used in the study. They were purchased from KEMRI and maintained at in IPR Animal Resources Department at rodents' holding facilities. The mice were fed with nutrients pellets (Laboratory chow from Unga Feeds ${ }^{\circledR} \mathrm{CO}$ ) and supplemented with carrots and kale leaves. Water was supplied to them $a d$ libitum. Biomphalaria pfeifferi snails were collected from irrigation canals in Mwea (Kirinyaga 
District). The snails were scooped out of the water using a sieve attached to a long pole. The snails collected from Mwea were carried in plastic containers lined with damp cotton wool and transported to the snail room at IPR laboratory. The snails were screened for the presence of schistosomes.

\section{Experimental Design}

$\mathrm{BALB} / \mathrm{c}$ mice were placed into four groups of 18 mice each, of foot protein (FT), digestive gland (DG), infected control (IC) and normal control (N). In group FT, mice were immunized three times with foot protein extract from snail, and challenged with normal cercaria of S. mansoni; Group DG, were vaccinated three times with digestive gland protein extract, then challenged with $S$. mansoni cercariae; Group IC, mice were used as infected control and were infected with normal S. mansoni cercariae. Group N, mice were used as naive control. The groups were differentiated by markings with picric acid on their body. Six mice were sampled from every group during every sampling time point except for naive control. Sampling involved; obtaining blood for serum, lymph nodes and spleen to prepare cells for culture, at week two and four post infection (p.i). At week six post challenge (p.c), blood for serum was obtained from all mice that were perfused to recover adult worms.

\section{Preparation of immunizing agent}

Off springs of B. pfeifferi snails maintained at IPR for over five years, were used for preparation of soluble proteins. Foot and digestive gland were obtained from the snail and placed in labeled separate eppendorf tubes containing phosphate buffered saline (PBS x1) (Yole et al. 1996). The samples were homogenized using a glass mortar and pestle. The homogenate was then centrifuged for $1 \mathrm{hr}$ at 14,000 $\mathrm{g}$ at 4 degrees Celsius. The supernatant was obtained and assayed for protein concentration using the microtitre plate technique. Protein assay estimation was done in serial doubling dilution where the BIO-RAD dye was added to the aliquots, then incubated for $1 \mathrm{hr}$. The protein concentrations were read using ELISA reader at wavelength of 595nm (Yole et al., 1996).

\section{Immunization of $B A L B / c$ mice with foot protein and digestive gland}

The protein extracts were used as immunizing agents. Fifty micrograms of each protein was mixed with $100 \mu \mathrm{l}$ of complete Freud's adjuvant and used for immunizing the mice during the first vaccination. In the second and third booster $50 \mu \mathrm{g}$ of each protein was mixed with $100 \mu \mathrm{l}$ of incomplete Freud's adjuvant. The immunization was done intraperitoneally using $1 \mathrm{ml}$ syringe and needle. The vaccination was done to two groups, one receiving foot protein (FT) and the other digestive gland (DG). The mice in the two groups were immunized three times, at intervals of two weeks. One week after the final immunization, the mice were challenged with the normal S. mansoni cercariae (Yole et al., 1996).

\section{Parasite and intermediate host}

Twenty four hour faecal samples from olive baboons, housed at IPR primate colony, with chronic S. mansoni infection, were screened for S. mansoni eggs. The eggs were hatched and 5-8 miracidia were picked up from the Petri dish using a drawn out Pasteur pipette with a rubber bulb, under the dissecting microscope. The miracidia were dispensed into each well of a 24 well culture plate (Nunclon, Denmark). Snails from the malacology laboratory were transferred individually into the wells and the plates covered to prevent the snails from crawling out. The set-up was left for 30 minutes to allow parasite penetration after which the 
snails were transferred to snail tanks. The patent period for $S$. mansoni is five weeks. At four weeks p.i, the tanks were covered with dark cloth to prevent trickle shedding of cercariae. The procedure was carried out similar to that of Yole et al. (1996).

\section{Shedding of cercaria from infected snails}

Infected snails were shed and cercariae concentration in the suspension was estimated by counting three $50 \mu \mathrm{l}$ aliquots under the dissecting microscope. An average of cercarial number was taken and used to calculate the concentration of cercariae per milliliter. This was used to determine the volume of the suspension that was required to infect each mouse with 250 cercariae ( Smithter \& Terry 1965).

\section{Challenge of mice with the S. mansoni}

Mice in groups FT (immunized with snail's foot protein), DG (immunized with snail's digestive gland protein) and IC (not immunized), were anaesthetized with ketamine/xylazine mixture (20:1 made by adding $0.5 \mathrm{ml}$ of xylazine to $10 \mathrm{ml}$ of ketamine). Anaesthesia was delivered as $0.02 \mathrm{ml}$ per $30 \mathrm{~g}$ mouse body weight intraperitoneally. Once unconscious, the mice were arranged on a wooden infecting rack. Cotton wool, dipped in water, was used to clean and wet the shaven area to allow easy penetration of the cercariae. Metal rings, $1 \mathrm{~cm}$ diameter, were placed on the shaven area and cercarial suspension dispensed into the metal ring using a $1 \mathrm{ml}$ micropipette. Cercariae were allowed to penetrate for 30 minutes (Smithter \& Terry, 1965).

\section{Sampling and preparation of lymph nodes}

At each sampling point (weeks 2, 4 and 6) post challenge (p.c), six mice from each group were anaesthetized. A small incision was made at the centre of the abdominal skin and the skin torn around the waist of the mouse. The skin was then pulled up to expose the thoracic region and the abdominal wall was exposed by pulling the mouse skin to the groin region. Inguinal lymph nodes and the auxillary lymph nodes were removed carefully and transferred into incomplete medium (RPMI 1640, 0.1\% Gentamycin, 5x10 B mecaptoethanol) in a Petri-dish (Yole et al., 1996) in a sterile biosafety hood. They were teased using a sharp sterile forceps to release lymphocytes. The suspension was dispensed in $15 \mathrm{ml}$ centrifuge tube and sterile incomplete medium (RPMI 1640, 0.1\% Gentamycin, 5x10-

${ }^{5} \mathrm{~B}$ mecaptoethanol) added up to $10 \mathrm{ml}$ mark. The cells were centrifuged at $450 \mathrm{~g}$ for 10 minutes for effective sedimentation. The supernatants were discarded leaving a pellet. The cells in the pellet were resuspended and washing was done two times. After the final wash, the cells were resuspended in $1 \mathrm{ml}$ of complete medium (incomplete medium fortified with $10 \%$ fetal calf serum) and counted in the haemocytometer chamber using Trypan blue. The counting was done under a microscope using X40 magnification. The cells were then adjusted to $3 \times 10^{6}$ cells $/ \mathrm{ml}$ and cells were used for culture supernatant (Yole et al., 1996).

\section{Sampling and preparation of spleen}

The spleen, from each mouse was removed and placed into incomplete medium in a Petri dish in a sterile culture hood. A $10 \mathrm{ml}$ syringe piston was used to squash the spleen. The dispersed cells were then dispensed in $15 \mathrm{ml}$ tube and topped up with incomplete media. The cells were washed and counted. However, the cells were resuspended in $4 \mathrm{ml}$ of complete medium in readiness for counting. The cells were used to culture supernatant for the cytokine assays (Yole et al., 1996). 


\section{Immunological assays}

Culture Supernatant: Flat-bottomed 48-well microtitre plate was used for culture and $6 \times 10^{5}$ cells from lymph nodes and spleen. Duplicate wells were set for each regime. Negative control had only medium and cells. Positive control had $1 \mu \mathrm{g} / \mathrm{ml}$ of Concanavalin A and test wells, $10 \mu \mathrm{g} / \mathrm{ml}$ well of Soluble worm antigen preparation (SWAP) and 0-3 hrs release protein. The total volume of culture medium per well was $400 \mu \mathrm{l}$. The plates were incubated at $37^{\circ} \mathrm{C}, 5 \% \mathrm{CO}_{2}$ for $48 \mathrm{hrs}$ for Con $\mathrm{A}$ and $72 \mathrm{hrs}$ for the other set-ups. At the end of the specified incubation period, supernatants were collected and used for ELISA (Yole et al., 1996).

Antibody assay (IL-5 and IFN- $\gamma$ ): Nunc-Immuno ${ }^{\mathrm{TM}}$ (MaxiSorp ${ }^{\mathrm{TM}}$ Surface) ELISA plates were coated with $50 \mu \mathrm{l}$ of $5 \mu \mathrm{g} / \mathrm{ml}$ solution of monoclonal anti IL-5-antibody and IFN- $\gamma$ antibody. They were incubated overnight at $4^{\circ} \mathrm{C}$. The plates were then washed six times with $0.05 \%$ Tween 20 in PBS and $100 \mu \mathrm{l} /$ well blocking buffer, $0.1 \%$ Bovine Serum Albumin (BSA) was added. The plates were incubated for $1 \mathrm{hr}$ at $37^{\circ} \mathrm{C}$ and thereafter washed six times and $50 \mu \mathrm{l} /$ well of samples and standards, in duplicates, were added. Plates were incubated for $2 \mathrm{hrs}$ at $37^{\circ} \mathrm{C}$. They were then washed six times and $50 \mu \mathrm{l} / \mathrm{well}$ of $3 \mu \mathrm{g} / \mathrm{ml} \mathrm{rabbit} \mathrm{anti-}$ mouse IL- 5 and IFN- $\gamma$ (mAb TRFK4 - biotin) added. The plates were then incubated for $1 \mathrm{hr}$ at $37^{\circ} \mathrm{C}$. The plates were washed six times and $50 \mu \mathrm{l} /$ well of Streptavidin - HRP (conjugate) added. They were incubated for $1 \mathrm{hr}$ at $37^{\circ} \mathrm{C}$ and washed six times and $50 \mu \mathrm{l} /$ well of the substrate (Sure Blue ${ }^{\mathrm{TM}} \mathrm{TMB}$ ) added. The plates were incubated at $37^{\circ} \mathrm{C}$ in the dark for 30 minutes. Optical density was read at $630 \mathrm{~nm}$ in an ELISA microplate reader (Dynatech MRX).

\section{Data analysis}

The student's $t$-test was used to analyze significance levels. $P$ values $<0.05$ were considered significant.

\section{Results}

IFN $-\gamma$ production to $0-3 \mathrm{hr}$ antigen by lymph node cells following infection with S. mansoni

The IFN $-\gamma$ production to $0-3 \mathrm{hr}$ antigens are shown in Figure 1. For group DG, at week 2 p.i the production was $12032 \mathrm{pg} / \mathrm{ml}$ which then dropped to low levels of $109 \mathrm{pg} / \mathrm{ml}$ at week 4 . There was no measurable level of IFN $-\gamma$ for FT, at week 2 p.i. However, at week 4 the group recorded a production of $84 \mathrm{pg} / \mathrm{ml}$. The production for IC, at week 2 was $1141 \mathrm{pg} / \mathrm{ml}$ which then reduced to $335.75 \mathrm{pg} / \mathrm{ml}$ at week 4 . There was a significance difference $(\mathrm{p}<0.05)$ between week 2 and week 4 in DG, unlike groups FT and IC which showed no significance difference $(p>0.05)$ between week 2 and week 4 . The production of IFN $-\gamma$ in DG was significantly higher than IC at week $2(\mathrm{p}<0.05)$. Group FT at week 2 , showed no production for IFN $-\gamma$ as compared to group IC which had a higher production than FT, but the difference was not significant ( $p>0.05)$. At week 4 , the levels of IFN $-\gamma$ in DG had reduced with no significant difference ( $p>0.05)$ compared to IC. At week 4 , the levels of IFN $-\gamma$ in FT had increased slightly with no significance difference ( $>0.05)$ compared to IC. At week 2 , the response of IFN $-\gamma$ in DG was significantly higher $(\mathrm{p}<0.05)$ than in group FT. At week 4 , Groups DG and FT showed no significant difference in the IFN $-\gamma$ production (Figure 1). 


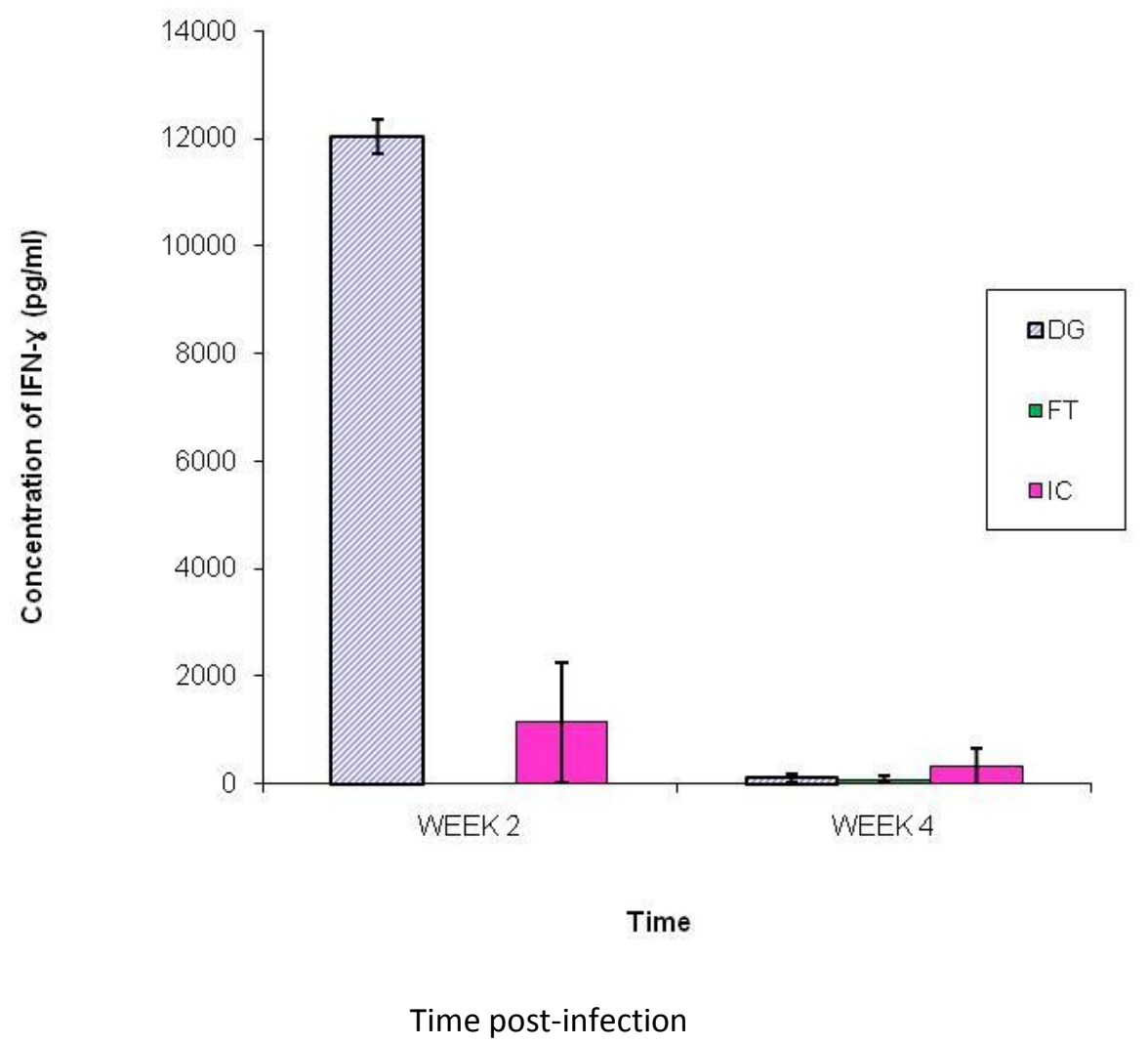

Figure 1: IFN $-\gamma$ production to $0-3 \mathrm{hr}$ antigen in lymph node cells at weeks 2 and 4 following infection with S. mansoni

IFN - $\gamma$ production to SWAP antigen by lymph node cells following infection with S. mansoni

The IFN $-\gamma$ production to SWAP antigen are shown in Figure 2. The response of IFN $-\gamma$ in DG, at week 2 p.i was $109 \mathrm{pg} / \mathrm{ml}$, but increased to higher levels of $11279.5 \mathrm{pg} / \mathrm{ml}$ at week 4 . Group FT, showed low production $(84 \mathrm{pg} / \mathrm{ml})$ at week 2 p.i, but at week 4 there was some slight increase in the production $(304.5 \mathrm{pg} / \mathrm{ml})$. At week 2 , the IC group showed a production of $335.75 \mathrm{pg} / \mathrm{ml}$ which increased to $2779.5 \mathrm{pg} / \mathrm{ml}$ at week 4 . There was a significant difference $(p<0.05)$ in DG between week 2 and week 4 , unlike groups FT and IC which showed no significant difference $(\mathrm{p}>0.05)$ between these two time points. The production of IFN $-\gamma$ in DG was lower than group IC at week 2 , but there was no significant difference ( $>0.05)$. Group FT at week 2, showed a lower production of IFN $-\gamma$ than group IC though not significantly different $(\mathrm{p}>0.05)$. At week 2 , the production of IFN $-\gamma$ in groups DG and FT was not significantly different $(\mathrm{p}<0.05)$. At week 4 , the levels of IFN $-\gamma$ in DG had increased significantly $(p<0.05)$ when compared to IC. At week 4 , the levels of IFN $-\gamma$ in FT had increased slightly with no significant difference $(p>0.05)$ as compared to group IC. At week 4, Groups DG and FT showed significant difference $(\mathrm{p}<0.05)$ in the production of IFN $-\gamma$; DG had a higher production than group FT. 


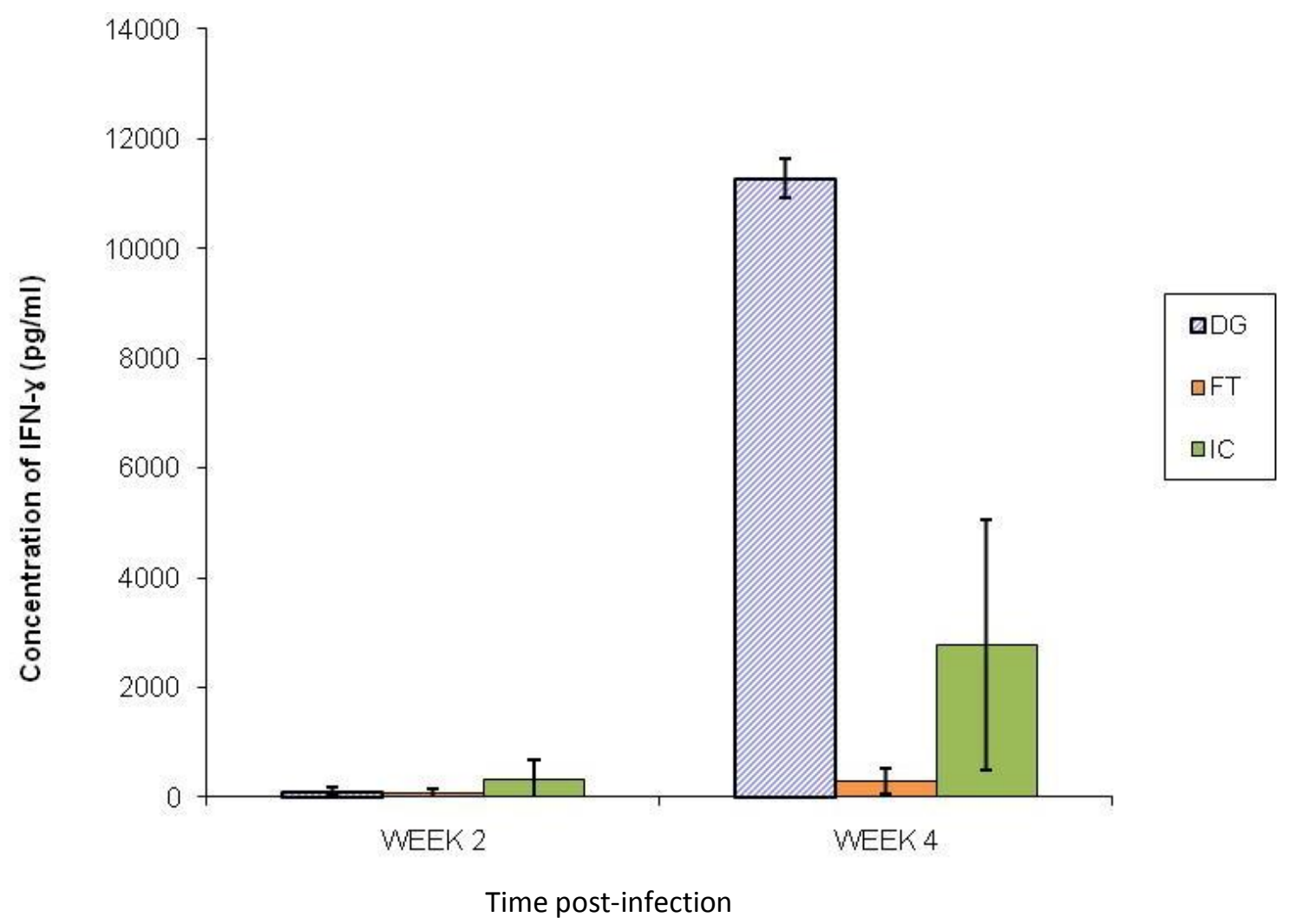

Figure 2: IFN $-\gamma$ production to SWAP antigen by lymph node cells at weeks 2 and 4 following infection with $S$. mansoni

IFN $-\gamma$ production to $0-3 \mathrm{hr}$ antigen by spleen cells following infection with $\mathrm{S}$. mansoni The IFN $-\gamma$ production to $0-3 \mathrm{hr}$ cercarie antigens are shown in Figure 3. The response of IFN $-\gamma$ in spleen cells in DG, at week 2 p.i was high $(13624.5 \mathrm{pg} / \mathrm{ml})$ but decreased at week 4 to $445 \mathrm{pg} / \mathrm{ml}$. The response of the FT group, was low at week 2 p.i $(18.5 \mathrm{pg} / \mathrm{ml})$, however at week 4 there were no measurable levels. In IC, at week 2 , the response was minimal but at week 4 there was a response of 560pg/ml. Groups DG and IC at week 2 and week 4 showed a significant difference $(P<0.05)$; FT response between week 2 and week 4 was not significant $(P>0.05)$. The response of IFN $-\gamma$ in spleen cells in the DG was higher than IC at week 2; this showed significant difference $(P<0.05)$ between the two groups. At week 2 , FT had a slightly higher response as compared to IC but the response was not significantly different $(P>0.05)$. At week 2 , the response of IFN $-\gamma$ in groups DG was significantly higher $(P<0.05)$ than group FT. At week 4, the levels of IFN $-\gamma$ in spleen between DG and IC was not significantly different $(P>0.05)$. At week 4 , the levels of IFN $-\gamma$ in group FT was lower than IC, and the difference was significant $(\mathrm{p}<0.05)$. At week 4, Groups DG and FT showed significant difference $(P<0.05)$ in the response to IFN $-\gamma$, where group DG had a higher production than group FT. 


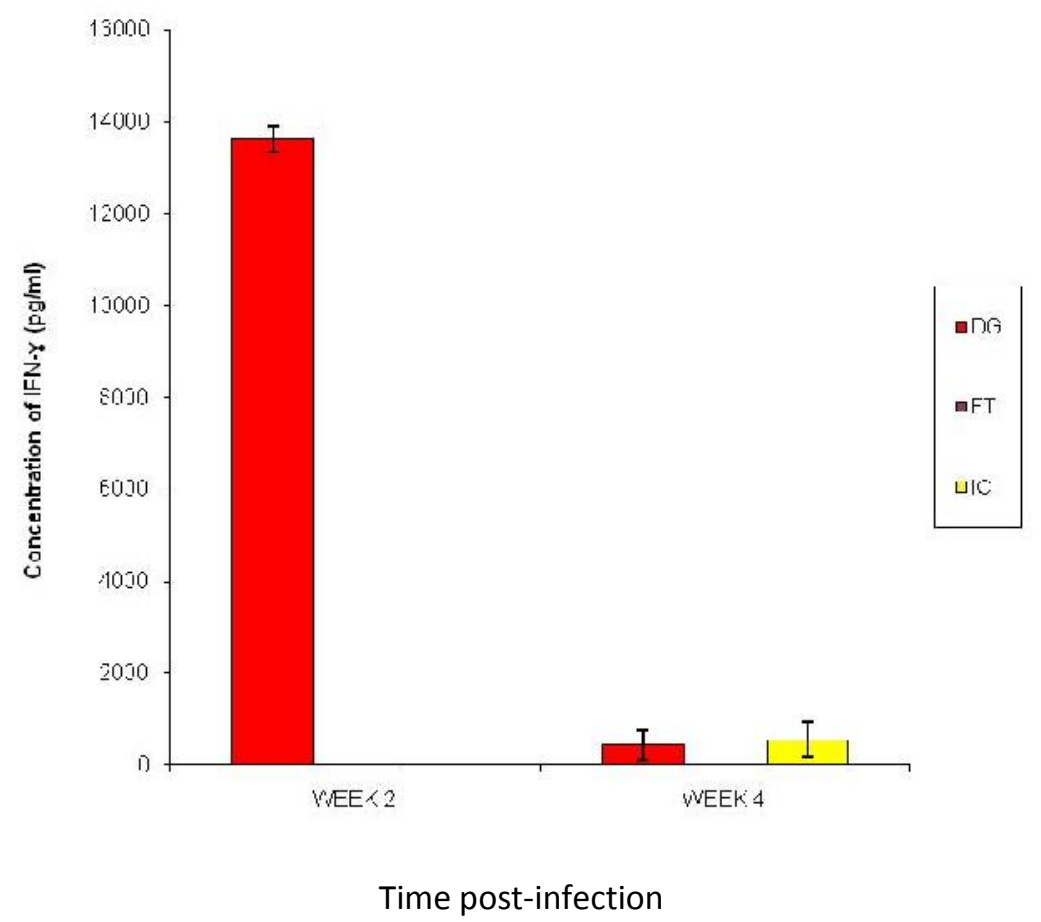

Figure 3: IFN $-\gamma$ production to $0-3 \mathrm{hr}$ antigen by spleen cells at weeks 2 and 4 following $S$. mansoni infection

IFN - $\gamma$ production to SWAP antigen by spleen cells following infection with $\mathrm{S}$. mansoni The production of IFN $-\gamma$ to SWAP antigen in spleen cells is as shown in Figure 4. In DG, at week 2 p.i the production was low $(144 \mathrm{pg} / \mathrm{ml})$ but it increased to a high level at week 4 to $8717.5 \mathrm{pg} / \mathrm{ml}$. In FT, the production was low of $350.25 \mathrm{pg} / \mathrm{ml}$ at week $2 \mathrm{p} . \mathrm{i}$, but at week 4 the production had increased to $2312.5 \mathrm{pg} / \mathrm{ml}$. In group IC, at week 2 , there was low production of $157.25 \mathrm{pg} / \mathrm{ml}$ which increased at week 4 to $6052.5 \mathrm{pg} / \mathrm{ml}$. There was significant difference $(P<0.05)$ of all groups between week 2 and week 4 . The production of IFN $-\gamma$ in spleen cells in the DG was lower than group IC at week 2 with no significant difference $(P>0.05)$. At week 2, FT showed higher production of IFN $-\gamma$ than group IC but the difference was not significant $(P>0.05)$. At week 2 , the production of IFN $-\gamma$ in groups FT was higher than DG with no significant difference $(P>0.05)$. At week 4 , the production in DG had increased but with no significant difference $(P>0.05)$ as compared to IC. At week 4 , the levels of IFN $-\gamma$ in IC was higher than group FT with significant difference $(P<0.05)$. At week 4 , DG and FT showed significant difference $(P<0.05)$ in the production of IFN $-\gamma$, where group DG had a higher concentration than group FT. 


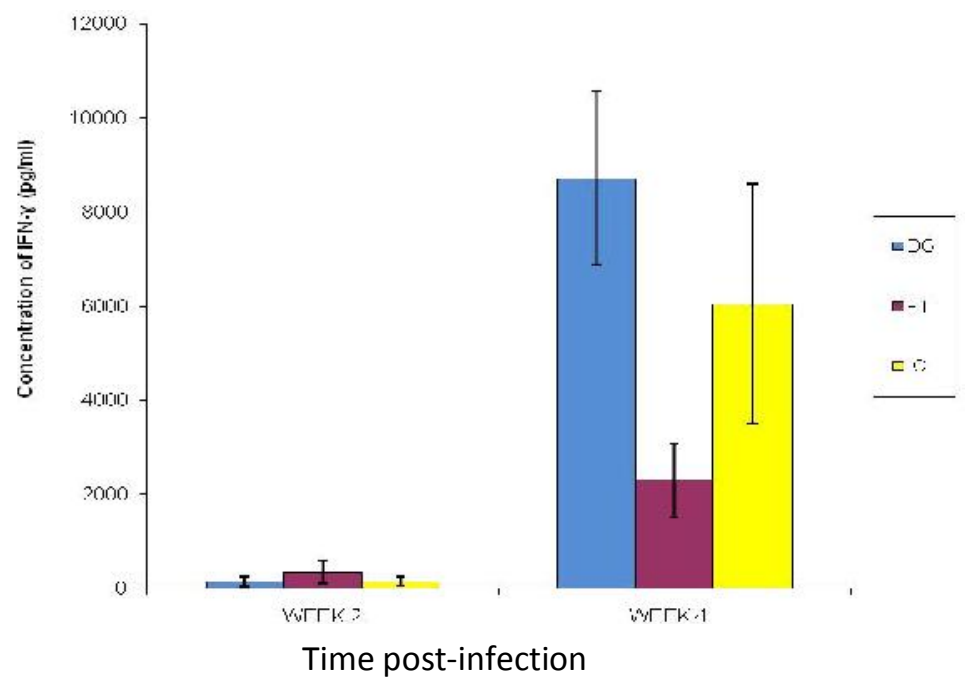

Figure 4: IFN $-\gamma$ production to SWAP antigen by spleen cells at weeks 2 and 4 following $S$. mansoni infection

\section{IL -5 production to $0-3 \mathrm{hr}$ antigen by lymph nodes S. mansoni infection}

The production of IL - 5 to $0-3 \mathrm{hr}$ antigen in lymph nodes cells was $472.9 \mathrm{pg} / \mathrm{ml}$ in DG at week 2 p.i, which later became minimal, below measurable levels at week 4 (Figure 5). For FT and IC, they had levels that were not measurable both at week 2 and week 4 . Group DG was the only one which showed significant difference $(P<0.05)$ between week 2 and week 4 .

The production of IL - 5 to $0-3 \mathrm{hr}$ antigen in lymph nodes cells in the group DG was higher than group IC at week 2 which showed significant difference $(P<0.05)$. At week 2 , the production of IL - 5 in group DG was significantly higher than group FT $(P<0.05)$. At week 4 , the levels of IL - 5 in spleen cells in group DG had reduced below measurable levels with no significant difference $(P>0.05)$ as compared to IC. At weeks 2 and 4 , FT and IC showed no production of IL -5 with no significant difference $(P>0.05)$.

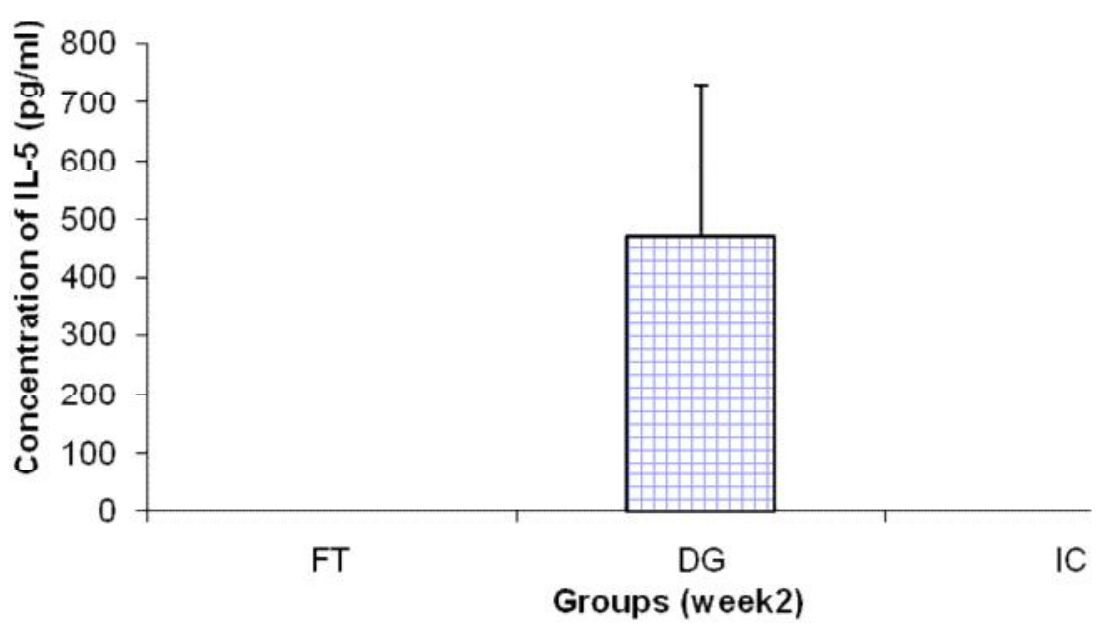

Figure 5: IL -5 production to $0-3 \mathrm{hr}$ antigen by lymph nodes in week 2 following S. mansoni infection 


\section{IL - 5 production to SWAP antigen by lymph nodes following S. mansoni infection}

The production of IL - 5 to SWAP in lymph nodes cells was $746.8 \mathrm{pg} / \mathrm{ml}$ for DG at week 2 p.i, which later became minimal at week 4 . In FT and IC, levels of IL-5 which were minimal at week 2. The production for the groups FT, DG and IC was hardly noticeable at week 4 . Group DG showed significant difference $(P<0.05)$ between week 2 and week 4 . The production of IL - 5 to SWAP antigen in lymph nodes cells in the DG was higher than group IC at week 2 which showed significant difference $(P<0.05)$. At week 2 , the production of IL 5 in group DG was significantly higher than group FT $(P<0.05)$. At week 4 , the levels of IL - 5 in spleen cells in group DG had reduced below measurable levels with no significant difference ( $P>0.05)$ as compared to IC. At weeks 2 and 4, FT and IC showed no production of IL -5 with no significant difference $(P>0.05)$.

\section{IL - 5 production to $0-3 \mathrm{hr}$ antigen by spleen cells following S. mansoni infection}

The production of IL - 5 to $0-3 \mathrm{hr}$ antigen in lymph nodes cells was $291.25 \mathrm{pg} / \mathrm{ml}$ in DG at week 2 p.i, which later became minimal at week 4. Groups FT and IC had minimum levels which were not measurable both at week 2 and week 4 . The production of the groups was minimal at week 4 . Group DG was the only one that showed significant difference $(P<0.05)$ between week 2 and week 4 . The production of IL - 5 in spleen cells in the group DG was significantly higher than IC at week $2(P<0.05)$. At week 4 , the levels of IL - 5 in spleen cells in group DG had reduced below measurable levels with no significant difference $(p>0.05)$ between the groups (DG and IC). At weeks 2 and 4, groups FT and IC showed no production of IL -5 with no significant difference $(P>0.05)$. At week 2 , the production of IL 5 in group DG was significantly higher than group FT $(P<0.05)$.

\section{IL - 5 production to SWAP antigen by spleen cells following S. mansoni infection}

The production of IL - 5 in spleen cells was below measurable levels in the groups DG, FT and IC both at weeks 2 and 4 p.i.

\section{Discussion}

It is speculated that $S$. mansoni infections induce an immune response dominated by Th2 cells, whereas a Th1 predominant response strongly correlates with resistance to infection. A key distinction between the Th1 versus Th2 pathways lies in the source of different cytokines involved. Th1 responses are typically characterized by the secretion of IFN- $\gamma$ and IL-2. However, Th2 responses are characterized by the secretion of IL-4, IL-5, IL-6 and IL-10. The vaccination-induced Th1-type response plays an important role in anti-schistosome infection by producing cytokines, such as IFN- $\gamma$ and IL-2. It has been shown that, at an early stage of infection, the host's response against the parasite is a Th1-type one. Epidemiological surveys of schistosomiasis showed the individual with a high level of IFN- $\gamma$ was significantly correlated with resistance to schistosome infection. In animal models with schistosome infection, it has been observed that IFN- $\gamma$ can suppress granuloma formation in vivo, and decrease the size of pulmonary granulomas and the extent of hepatic fibrosis (Reynolds et al., 2004).

With regard to cytokines assessed in this study, it sought to asses those that are reported to be differentially produced by two different T-helper subsets. Mosmann et al., 1986, have shown that those cells designated TH-1 produce IFN $-\gamma$, whereas those designated TH-2 produce IL -5 . 
IFN $-\gamma$ has been previously associated with in vitro killing of schistosomula by macrophages (Reynolds et al., 2004). The in vivo administration of anti-IFN $-\gamma$ has been shown to decrease protection in challenge infections (James \& Deblois, 1989). Mice immunized with DG had higher levels of IFN- $\gamma$ production throughout the experiment for both antigens (0-3hr and SWAP), and organs (lymph nodes and spleen). The difference was significantly higher when DG was compared to FT at all times. The same was true for IC except only one time point. FT responses were much lower than DG. However, a slight increase was noted from week 2 to week 4 , showing that the antigens stimulated the cells in this group to produce IFN- $\gamma$.

When the two groups were compared, DG initiated higher IFN- $\gamma$ production compared to FT. This shows that DG vaccine stimulated Th 1 cellular response to S. mansoni in mouse which leads to resistance of infection. In addition IFN- $\gamma$ is required for in vitro for granuloma formation (Reynolds et al., 2004). FT produced IFN- $\gamma$ as the infection progressed showing that IFN- $\gamma$ is involved in protection against S. mansoni induced by FT vaccine, though not as high as DG. 0-3hr responses were higher in week 2 when compared to SWAP which were higher in week 4 . This response is related to the stage "seen" (0-3hr-earlier stages and SWAP- week 4 worms) by the antigens.

IFN- $\gamma$ as a Th1 cytokine can activate macrophages to produce $\mathrm{NO}$ and other inflammatory mediators. In this study there was a high production of IFN- $\gamma$ in the experimental groups (DG and FT). The increased production may be responsible for worm reduction. The IFN- $\gamma$ stimulates natural killer (NK) and natural killer T (NKT) cells as part of the innate immune response once antigen-specific immunity develops. During acute infection of schistosomiasis, mice have shown to produce elevated levels of IFN- $\gamma$ in the liver, spleen and mesenteric lymph node (Hitoshi et.al., 1990).

IL-5 induces terminal differentiation of activated B cells into antibody-forming cells in mice and enhances proliferation and differentiation of eosinophils precursors into mature eosinophils in mice and humans. B-1 cells, which are distinguishable from B-2 cells by their cell surface markers, anatomical location and self-replenishing activity, constitutively express IL-5 receptor and respond to IL-5 for survival, proliferation and differentiation to antibody-secreting plasma cells (Hitoshi et. al., 1990). B-2 cells activated by antigen or mitogens in the presence of Th cells express IL-5 receptor and become responsive to IL-5 for maturation (Takatsu et al., 2009). According to the results obtained in the current study, only mice immunized with DG gave remarkable levels of IL-5 at week 2 for 0-3hr in lymph nodes and spleens and SWAP for lymph nodes only. The responses for FT and IC were hardly observable. This shows that DG highly stimulates production of IL-5, which is responsible for antibody production. The absence of IL-5 production at week 4 , is "normal", since the B cells have already been stimulated to produce antibodies, and hence IL-5 is no longer required. The results are supported by the fact that IL-5 expression decreases as the worm changes from schistosomula to adult worms. The IL-5 expression is linked to eosinophils that only play an important role at the start of the infection. The absence of IL- 5 responses to both antigens at week 4 could be due to low deposition of eggs in the tissues. This is explained that as adult worms mature the immune response shifts TH1 from towards TH2 due to egg deposition which was not the case in the study.

There has been a common view that Th1 and Th2 immune responses act antagonistically toward each other. For example, a strong Th1 immune response is necessary for an effective immune reaction to Mycobacterium leprae. A Th2 response led to high level of susceptibility during this infection, and animals as well as humans were unable to control 
the infection (Verhagen et. al., 1998). In C57BL/6 mice Leishmania major induces an effective Th1 immune response, while in BALB/c mice a nonprotective Th2 immune response is induced (Etges \& Muller, 1998). According to Scott (1991) gamma interferon (IFN- $\gamma$ ) as a typical Th1 cytokine and interleukin-5 (IL-5) as a typical Th2 cytokine have antagonistic effects. This explains why group DG had more worms recovered than group FT. Group DG had both IFN- $\gamma$ and IL-5 responses which were antagonistic to each other. On the other hand, FT had high responses of IFN- $\gamma$ and low responses of IL-5 which was minimal, hence lower worm counts. In conclusion, immunization with Foot protein (FT) and Digestive gland (DG) reduced worm burden. DG had higher cellular responses as shown by higher levels of IFN- $\gamma$ initially and thereafter.

\section{Acknowledgements}

We thank Mr. Kiio Kithome, Sammy Kisara, Simon Kiarie and Collins Kisara for their excellent technical assistance. The Institute of Primate Research Centre, Kenya is thanked for providing the laboratory facility to conduct this research.

\section{References}

Capron, A. \& Dessaint, J.P. (1985) Effector and Regulatory Mechanisms in Immunity to Schistosomes. Annual Review in Immunology 3, 455-476.

Capron, A., Dessaint, J.P., Capron, M., Ouma, J.H. \& Butterworth, A. (1987) Immunity to schistosomes: Progress towards Vaccine. Science 238, 1065-1072.

Capron, M. \& Capron, A. (1994) Immunology and Effector Cells in schistosomiasis. Science 264, 187.

Demeure, C.E., Rihet, P., Abel, L., Ouattara, M., Bourgois, A. \& Dessein, J. (1993) Resistance to schistosomiasis mansoni in humans: influence of IgE $\backslash \operatorname{IgG} 4$ balance and IgG2 in immunity to reinfection after chemotherapy. Journal of Infectious Diseases 168, 10001008.

Etges, R. \& Muller, I. (1998) Progressive disease or protective immunity to Leishmania major infection: the result of a network of stimulatory and inhibitory interactions. Journal of Molecular Medicine 76, 372-390.

Hitoshi, Y., Yamaguchi, N., Mita, S., Takaki, S., Tominaga, A. \& Takatsu, K. (1990) Distribution of IL-5 receptor-positive B cells. Expression of IL-5 receptor on Ly1(CD5)+ B cells. Journal of Immunology 144, 42-18.

James, S.L. \& Deblois, L.A. (1986) Induction of protective immunity against Schistosoma mansoni by a non living vaccine. II. Response of mouse strains with selective immune defects. Journal of Immunology 136, 3864-3871.

McManus, D.P. \& Loukas, A. (2008) Current status of vaccines for schistosomiasis. Clinical Microbiology Reviews 21, 225-242.

Mosmann, T.R., Cherwinski, H., Bond, M.W., Giedlin, M.A. \& Coffman, R.L. (1986) Two types of murine helper T-cell clones. I. Definition according to profiles of lymphokine activities and secreted proteins. Journal of Immunology 136, 2348-2357.

Oliveira, S.C., Fonseca, C.T., Cardoso, F.C., Farias, L.P. \& Leite, L.C.C. (2008) Recent advances in vaccine research against schistosomiasis in Brazil. Acta Tropica 108, 256262. 
Reynolds, S.R., Dahl, C.E. \& Harn, D.A. (2004) T and B epitope determination and analysis of multiple antigenic peptides for the Schistosoma mansoni experimental vaccine triose-phosphate isomerase. Journal of Immunology 152, 193-200.

Scott, P. (1991) IFN-gamma modulates the early development of Th1 and Th2 responses in a murine model of cutaneous leishmaniasis. Journal of Immunology 147, 3149-3155.

Smithers, S.R. \& Terry, R.J. (1965) The infection of laboratory hosts with the cercariae of mansoni and the recovery of adults' worms. Parasitology 5, 695-700.

Takatsu, K., Kouro, T. \& Nagai, Y. (2009) Interleukin 5 in the link between innate and acquired immune response. Advanced Immunology 101, 191-192.

Verhagen, C.E., van T.C., Pouw, K.A., Buffing, A., Chand, M.A., Faber, W.R., Aarden, L.A. \& Das, P.K. (1998) Type 1- and type 2-like lesional skin-derived Mycobacterium lepraeresponsive $\mathrm{T}$ cell clones are characterized by coexpression of IFN-gamma/TNF-alpha and IL-4/IL-5/IL-13, respectively. Journal of Immunology 160, 2380-2387.

Wilson, R.A. (1990) 'Leakey Livers': portal shunting and immunity to schistosomes. Parasitology Today 6, 354-358.

Yole, D.S., Pemberton, R., Reid, G.D. \& Wilson, R.A. (1996) Protective immunity to Schistosoma mansoni induced in the Olive baboon, Papio anubis, by the irradiated cercariae vaccine. Parasitology 12, 37-46. 